\title{
ANALISIS SALURAN PEMASARAN PEPAYA CALIFORNIA (Suatu Kasus di Desa Sukajaya Kecamatan Pamarican Kabupaten Ciamis)
}

\author{
ANALYSIS OF CALIFORNIA PAPAYA MARKETING CHANNELS \\ (A Case in Sukajaya Village, Pamarican District, Ciamis Regency)
}

\author{
HADI PERMANA ${ }^{1 *}$, TRISNA INSAN NOOR ${ }^{2}$, AGUS YUNIAWAN ISYANTO ${ }^{1}$ \\ ${ }^{1}$ Fakultas Pertanian Universitas Galuh \\ ${ }^{2}$ Fakultas Pertanian Universitas Padjajaran \\ *Email: permanahadi2405@gmail.com
}

\begin{abstract}
ABSTRAK
Tujuan dari penelitian ini adalah untuk mengetahui: 1) Saluran pemasaran pepaya California di Desa Sukajaya Kecamatan Pamarican Kabupaten Ciamis, 2) Besarnya biaya, marjin dan keuntungan pemasaran pepaya California di Desa Sukajaya Kecamatan Pamarican Kabupaten Ciamis, 3) Efisiensi pemasaran pepaya California di Desa Sukajaya Kecamatan Pamarican Kabupaten Ciamis, dan 4) Besarnya bagian harga yang diterima petani dari harga yang dibayar konsumen (farmer's share). Hasil penelitian menunjukan: 1) Terdapat 3 saluran pemasaran pepaya California di Desa Sukajaya Kecamatan Pamarican Kabupaten Ciamis, yaitu Saluran I (produsen - konsumen), Saluran II (produsen - pedagang pengecer - konsumen), dan Saluran III (produsen - pedagang pengumpul pedagang besar - pedagang pengecer - konsumen). 2) Biaya pemasaran pada saluran II sebesar Rp $230,00 / \mathrm{kg}$, dan pada saluran III sebesar Rp 1.000,00/kg. Marjin pemasaran pada Saluran II sebesar Rp $1.900 / \mathrm{kg}$, dan Saluran III sebesar Rp 4.200/kg. Keuntungan pemasaran pada Saluran II sebesar Rp $1.670,00 / \mathrm{kg}$, dan Saluran III sebesar Rp 3.300,00/kg. 3) Efisiensi pemasaran pada Saluran I sebesar 5,43\%, Saluran II sebesar 9,61\%, dan Saluran III sebesar 43,47\%. 4) Farmer's share pada saluran I sebesar 57,50\%, Saluran II sebesar 57,78\%, dan Saluran III sebesar 35,38\%.
\end{abstract}

Kata kunci: Saluran Pemasaran, papaya California

The purpose of this research is to find out: 1) California papaya marketing channel in Sukajaya Village, Pamarican District, Ciamis Regency, 2) Cost, margin and profit of California papaya marketing in Sukajaya Village, Pamarican District, Ciamis Regency, 3) Efficiency of California papaya marketing in Sukajaya Village, Pamarican District Ciamis Regency, and 4) The amount of the price that farmers receive from the price paid by the consumer (farmer's share). The results showed: 1) There were 3 California papaya marketing channels in Sukajaya Village, Pamarican District, Ciamis Regency, namely Channel I (producer - consumer), Channel II (producer - retailer - consumer), and Channel III (producer - trader - wholesaler - retailers - consumers). 2) Marketing costs for Channel I are Rp 00/kg, Channel II is Rp 230.00/kg, and Channel III is Rp $1,000.00 / \mathrm{kg}$. Marketing margin in Channel I is Rp 0/kg, Channel II is Rp 1,900/kg, and Channel III is $R p$ 4,200/kg. The marketing profit on Channel I was Rp 0/kg, Channel II was R 1,670.00/kg, and Channel III was Rp 3,300.00/kg. 3) Marketing efficiency in Channel I was 5.43\%, Channel II was 9.61\%, and Channel III was 43.47\%. 4) Farmer's share in Shannel I was 57.50\%, Channel II was $57.78 \%$, and Channel III was $35.38 \%$.

Keywords: Marketing Channels, California papaya

\section{PENDAHULUAN}

Sektor pertanian di Indonesia masih memegang peranan penting dari keseluruhan perekonomian nasional. Hal ini ditunjukan oleh banyaknya penduduk dan tenaga kerja yang hidup atau bekerja di sektor pertanian. Salah satu subsektor pertanian yang saat ini banyak digeluti 
masyarakat yaitu subsektor hortikultura. Hortikultura merupakan subsektor pertanian penting setelah pangan untuk memenuhi kebutuhan manusia, khususnya tanaman buah dan sayuran yang merupakan komoditas hortikultura yang berkembang pesat di Indonesia. Salah satu tanaman hortikultura yang dibudidayakan di Indonesia adalah pepaya.

Provinsi Jawa Barat merupakan salah satu daerah penghasil pepaya di Indonesia. Salah satu daerah di Jawa Barat yang merupakan penghasil pepaya adalah Kabupaten Ciamis (BPS Jawa Barat, 2019). Kabupaten Ciamis pada tahun 2018 memiliki produksi pepaya sebesar 107.297 kwintal. Hal ini menunjukan bahwa Kabupaten Ciamis memiliki potensi produksi buah pepaya yang sangat besar di Jawa Barat. Kabupaten Ciamis juga menempati peringkat ke 3 penghasil buah pepaya di Jawa Barat setelah Kabupaten Sukabumi dan Kota Banjar.

Kecamatan Pamarican merupakan kecamatan di Kabupaten Ciamis yang dikenal sebagai penghasil buah-buahan, salah satunya buah pepaya. Diketahui hasil produksi buah pepaya di Kecamatan Pamarican memiliki produksi tinggi dibandingkan dengan produksi di kecamatan lainnya. Problema fluktuasi harga pepaya California selalu menjadi kekuatiran bagi petani. Pada saat tertentu harga pepaya California anjlok karena beberapa faktor, diantaranya cuaca yang membaik yang mengakibatkan produksi melimpah sehingga pasokan ke pasar meningkat, sedangkan permintaan cenderung tetap. Saluran pemasaran adalah suatu jalan yang di ikuti dalam mengalihkan pemilikan secara langsung atau tidak langsung atas suatu produk dan produk akan berpindah tempat dari produsen ke konsumen akhir.

Penelitian ini bertujuan untuk mengetahui: 1).Saluran pepaya California di Desa Sukajaya Kecamatan Pamarican Kabupaten Ciamis. 2) Margin dan keuntungan pemasaran pepaya California di Desa Sukajaya Kecamatan Pamarican Kabupaten Ciamis. 3) Efisiensi pemasaran pepaya California di Desa Sukajaya Kecamatan Pamarican Kabupaten Ciamis. 4) Farmer share pada pemasaran pepaya California di Desa Sukajaya Kecamatan Pamarican Kabupaten Ciamis.

\section{METODE PENELITIAN}

Jenis penelitian yang digunakan adalah metode survey dengan mengambil kasus di Desa Sukajaya Kecamatan Pamarican Kabupaten Ciamis. Menurut Sugiono (2014), metode survey adalah metode penelitian yang digunakan untuk 
mendapatkan data dari tempat tertentu yang alamiah (bukan buatan), tetapi penelitian melakukan perlakuan dalam pengumpulan data, misalnya dengan memberikan kuesioner, membaca literatur, dan sebagainya.

Data yang digunakan dalam penelitian ini terdiri atas data primer dan sekunder. Menurut Sugiono (2012), data primer adalah sumber data yang langsung memberikan data kepada pengumpul data. Data primer diperoleh secara langsung dari petani dan pelaku pemasaran dengan metode wawancara berdasarkan daftar pertanyaan yang telah disiapkan (kuesioner). Data sekunder adalah sumber data yang tidak langsung memberikan data kepada pengumpul data, misalnya lewat orang lain atau lewat dokumen. Data primer diperoleh melalui studi literatur serta studi dokumentasi dari instansi terkait, perpustakaan, internet, serta beberapa metode penelitian terdahulu yang berkaitan dengan penelitian ini

Desa Sukajaya Kecamatan Pamarican Kabupaten Ciamis dipilih sebagai lokasi penelitian secara purposive dengan pertimbangan merupakan salah satu sentra produksi pepaya California di Kabupaten Ciamis. Menurut Sugiyono (2012), purposive sampling adalah teknik penentuan sampel dengan pertimbangan tertentu. Petani papaya California di Desa Sukajaya Kecamatan Pamarican Kabupaten Ciamis sebanyak 20 orang dan seluruhnya diambil sebagai sampel penelitian atau dilaksanakan dilaksanakan sensus. Menurut Sugiono (2008) sensus adalah teknik penentuan sampel bila semua anggota populasi digunakan sebagai sampel.

Analisis saluran pemasaran pepaya California dari Desa Sukajaya Kecamatan Pamarican Kabupaten Ciamis dilakukan dengan cara menelusuri lembaga pemasaran yang terlibat dalam proses pemasaran komoditi pepaya mulai dari petani sampai pedagang pengecer.

Margin pemasaran merupakan selisih harga jual dengan harga beli. Besarnya margin pemasaran, dihitung dengan menggunakan rumus sebagai berikut (Sudiyono, 2004):

$\mathrm{M}=\mathrm{Hp}-\mathrm{Hb}$

Keterangan:

$\mathrm{M}=$ Margin pemasaran

$\mathrm{Hp}=$ Harga jual

$\mathrm{Hb}=$ Harga beli

Keuntungan pemasaran adalah selisih antara margin pemasaran dengan biaya yang dikeluarkan. Soekarwi (2002), menyatakan untuk menghitung keuntungan dapat dituliskan rumus sebagai berikut:

$\mu=\mathrm{m}-\mathrm{b}$

Keterangan:

$\mu=$ Keuntungan 
$\mathrm{m}=$ Margin tataniaga

$\mathrm{b}=$ Biaya yang dikeluarkan

Menurut Roesmawati

(2011),

efisiensi pemasaran dapat dihitung dengan menggunakan rumus sebagai berikut:

$E P=\left[\frac{T B}{T N P}\right] X 100 \%$

Keterangan:

ET = Efesiansi pemasaran (\%)

$\mathrm{TB}=$ Total biaya pemasaran $(\mathrm{Rp})$

$\mathrm{HLPB}=$ Total nilai produk $(\mathrm{Kg})$

Bagian harga yang diterima petani adalah perbandingan antara harga di tingkat petani dengan harga di tingkat konsumen. Menurut Sutarno (2014), besaranya bagian harga yang diterima petani dihitung dengan rumus sebagai berikut:

$\mathrm{Fs}=\frac{P f}{P r} x 100 \%$

Keterangan:

Fs = Bagian harga yang diterima oleh petani

Pf = Harga pepaya ditingkat petani

$\operatorname{Pr}=$ Harga pepaya ditingkat konsumen

\section{HASIL PENELITIAN DAN}

\section{PEMBAHASAN}

\section{Saluran Pemasaran}

Terdapat 3 saluran pemasaran pepaya California di Desa Sukajaya Kecamatan Pamarican Kabupaten Ciamis sebagaimana terlihat pada Gambar 1.

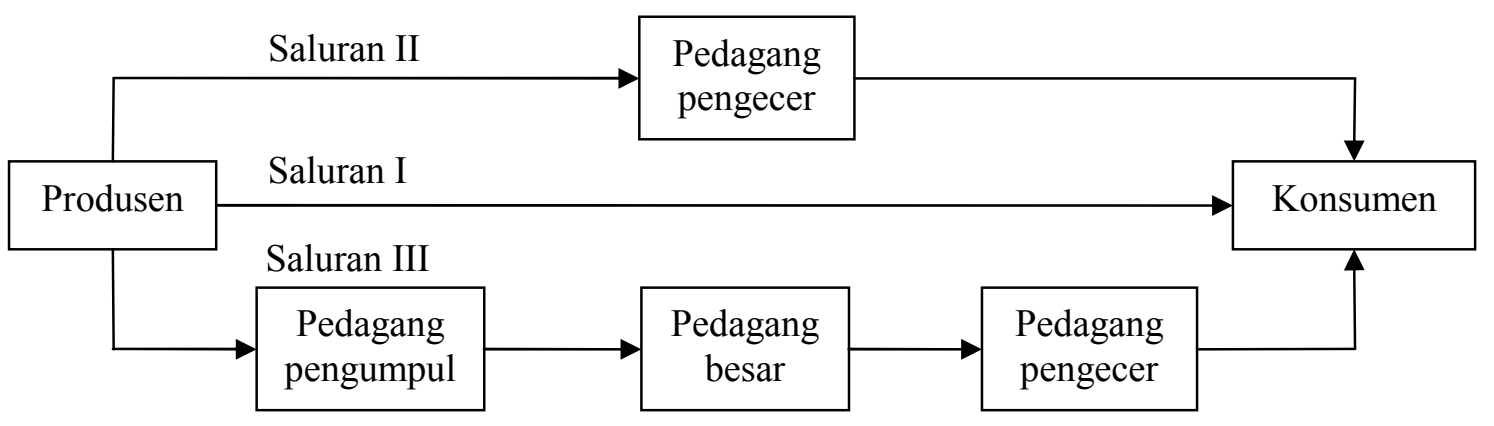

\section{Gambar 1. Saluran Pemasaran Pepaya California}

\section{Marjin Pemasaran}

Margin pemasaran adalah perbedaan harga di tingkat produsen dengan harga di tingkat konsumen pada produk yang sama yang dinyatakan dengan rupiah/kilogram. Untuk lebih jelasnya mengenai marjin pemasaran pada tiap-tiap saluran pemasaran dapat dilihat pada Tabel 1 . 
Tabel 1. Margin Pemasaran Pepaya California di Desa Sukajaya Kecamatan Pamarican Kabupaten Ciamis

\begin{tabular}{clccc}
\hline Saluran & Lembaga Pemasaran & Harga Beli(Rp/kg) & Harga Jual (Rp/kg) & Margin (Rp/kg) \\
\hline I & Petani & - & 4.000 & 0 \\
\hline II & Petani & - & 2.600 & 2.600 \\
& Pedagang Pengecer & 2.600 & 4.500 & 1.900 \\
\hline \multirow{2}{*}{ III } & Petani & - & 2.300 & 2.300 \\
& Pedagang Pengumpul & 2.300 & 3.800 & 1.500 \\
& Pedagang Besar & 3.800 & 5.000 & 1.200 \\
& Pedagang Pengecer & 5.000 & 6.500 & 1.500 \\
\hline
\end{tabular}

Berdasarkan Tabel 1 dapat diketahui bahwa marjin pemasaran pada saluran I sebesar Rp 0/kg. Marjin pemasaran pada saluran II untuk pedagang pengecer sebesar Rp 1.900 /kg, sedangkan untuk margin pemasaran pada saluran III untuk pedagang pengumpul $\mathrm{Rp} 1.500 / \mathrm{kg}$, pedagang besar Rp 1.200/kg dan pedagang pengecer Rp 1.500/kg.

\section{Efisiensi Pemasaran}

Untuk lebih jelasnya mengenai efisiensi pemasaran pada tiap-tiap saluran pemasaran dapat dilihat pada Tabel 2 .

Tabel 2. Efisiensi Pemasaran pada Setiap Saluran Pemasaran

\begin{tabular}{cccc}
\hline Saluran Pemasaran & Biaya Pemasaran (Rp/kg) & Nilai Produk (Rp/kg) & Ep (\%) \\
\hline I & 125,00 & $2.300,00$ & 5,43 \\
II & 250,00 & $2.600,00$ & 9,61 \\
III & $1.000,00$ & $2.300,00$ & 43,47 \\
\hline
\end{tabular}

Tabel 2 menunjukkan bahwa efisiensi pemasaran pada saluran I sebesar $5,43 \%$, itu karena biaya pemasarannya relatif kecil hanya sekitar Rp 125,00/kg sedangkan nilai produknya sebesar $\mathrm{Rp}$ 2.300/kg. Pada saluran pemasaran II Ep 9,61\%. Pada saluran pemasaran II ini biaya pemasarannya sekitar $\mathrm{Rp} 250,00 / \mathrm{kg}$ dan nilai produknya sebesar $\mathrm{Rp} 2.600 / \mathrm{kg}$. Efisiensi pemasaran pada saluran pemasaran III 43,47\%. Efisiensi pemasaran pada saluran pemasaran III ini nilai Ep semakin besar karena biaya pemasarannya pun semakin besar pula yaitu mencapai $\mathrm{Rp}$ $1.000,00 / \mathrm{kg}$. Dari ketiga saluran pemasaran tersebut dapat dilihat Ep yang paling efisien terdapat pada saluran I.

\section{Farmer's Share}

Besarnya farmer's share dari ketiga saluran pemasaran pepaya California di Desa Sukajaya Kecamatan Pamarican Kabupaten Ciamis dapat dilihat pada Tabel 3. 
Tabel 3. Farmer's Share pada Setiap Saluran Pemasaran

\begin{tabular}{cccc}
\hline Saluran Pemasaran & $\begin{array}{c}\text { Harga Jual Produsen } \\
\text { (Rp/kg) }\end{array}$ & $\begin{array}{c}\text { Harga Beli Konsumen } \\
(\mathbf{R p} / \mathbf{k g})\end{array}$ & $\begin{array}{c}\text { Farmer's share } \\
(\mathbf{\%})\end{array}$ \\
\hline I & 2.300 & 4.000 & 57,50 \\
II & 2.600 & 4.500 & 57,78 \\
III & 2.300 & 6.500 & 35,38 \\
\hline
\end{tabular}

Farmer's share pada saluran pemasaran I sebesar 57,50\%. Saluran I adalah saluran yang memberikan bagian harga terkecil untuk petani yaitu sebesar 57,50 dari harga yang dibayar konsumen. sementara pada saluran pemasaran II sebesar 57,78\% itu artinya produsen menerima harga sebesar $57,78 \%$ dari harga yang dibayarkan konsumen, dan Farmer's Share pada saluran pemasaran III sebesar 35,38\%. Pada saluran pemasaran satu dan tiga, harga di tingkat konsumen/petani adalah sama sebesar Rp 2.300,00

\section{KESIMPULAN DAN SARAN}

\section{Kesimpulan}

Berdasarkan hasil penelitian dan pembahasan, maka dapat ditarik kesimpulan sebagai berikut:

1. Terdapat 3 saluran pemasaran pepaya California di Desa Sukajaya Kecamatan Pamarican Kabupaten Ciamis, yaitu: Saluran Pemasaran I (produsen konsumen), Saluran Pemasaran II (produsen - pedagang pengecer konsumen), dan Saluran Pemasaran III (produsen - pedagang pengumpul - pedagang besar - pedagang pengecer konsumen).

2. Biaya pemasaran pada saluran I sebesar Rp 125,00/kg, saluran II sebesar Rp $230,00 / \mathrm{kg}$, dan pada saluran III sebesar Rp 1.000,00/kg. Sedangkan Marjin pemasaran pada saluran I sebesar Rp 0/kg, saluran II sebesar Rp 1.900,00/kg, dan pada saluran III sebesar Rp $4.300,00 / \mathrm{kg}$. Keuntungan pemasaran pada saluran I sebesar Rp 1.575,00/kg, saluran II sebesar Rp 1.670,00/kg, dan pada saluran III sebesar Rp 3.300,00/kg.

3. Episiensi Pemasaran pada saluran pemasaran I sebesar 5,43\%, saluran II sebesar 9,61\%, dan pada saluran III sebesar $43,47 \%$.

4. Farmer's Share pada saluaran pemasaran I sebesar 57,50, saluaran pemasaran II sebesar 57,78 dan pada saluaran pemasaran III sebesar 35,38.

\section{Saran}

1. Berdasarkan hasil penelitian yang telah dilakukan, maka disarankan agar petani dapat menjual langsung pepaya California ke konsumen akhir walaupun dalam jumlah sedikit sehingga dapat 
memperoleh keuntungan yang lebih tinggi.

2. Pepaya yang tergolong tidak layak dijual seharusnya bisa dimanfaatkan atau diolah menjadi berbagai produk seperti manisan pepaya dan sebagainya, sehingga dapat menambah penghasilan bagi para petani.

3. Untuk lembaga pemasaran yang terlibat dalam pemasaran pepaya California disarankan untuk menekan biaya pemasaran dengan menambah volume angkut serta dapat mengurangi biaya pengangkutan dan juga pengemasan harus lebih baik lagi sehingga risiko kerusakan dapat ditekan serendah mungkin.

\section{DAFTAR PUSTAKA}

Anindita, 2004. Pemasaran Hasil Pertanian. Surabaya: Penerbit Papyrus.

Ari, 2015. Analisis Kelayakan Usahatani Pepaya California di Desa Lembupurwo Kecamatan Mirit Kabupaten Kebumen

Ashari, S. 2004. Biologi Reproduksi Tanaman Buah-buhan Komersial. Malang: Penerbit: Banyu-media Publishing.

Badan Pusat Statistik Kabupaten Ciamis, 2019. Kecamatan Pamarican Dalam Data.

Badan Pusat Statistik Provinsi Jawa Barat, 2019. Jawa Barat Dalam Data.

Boyd et al. 2000 dalam Abednego. 2008. Manajemen Pemasaran; Suatu Pendekatan Stategis dengan
Orientasi Global. Jakarta: Penerbit Erlangga.

Daniel, M. 2002. Pengantar Ekonomi Pertanian: Penerbit Sinar Gradika Offset. Jakarta.

Dinas Pertanian dan Holtikultura Kabuten Ciamis, 2018. Rekap Realisasi Buah-Buahan Ciamis.

Direktorat Gizi, Depkes RI 2016. Kandungan Gizi pada Buah Pepaya. Jakarta.

Direktorat Jendaral Hortikultura. 2015. Perkembangan PDB Komuditas Hortikultura Indonesia. http://hortikultura.deptan.go.id (diakses 28 Maret 2019).

Fajar. 2008. Manajemen Pemasaran. Yogyakarta: Penerbit Graha Ilmu.

Haid, A. 2006. Tataniaga Pertanian. Universitas Hasanuddin.

Hutahuruk, J., 2003. Tataniaga Hasil Pertanian. UNIKA. Medan

Kantor Desa Sukajaya, 2019. E Data Menurut Luas Lahan, Usia, Mata Pencaharian dan Tingkat Pendidikan.

Kartasapoetra. G, Marketig Produk Pertanian dan Industri. Jakarta: Rineka Cipta.

Kelie, M. 2008. Bertanam Pepaya. Jakarta: Penebar Swadaya.

Kementerian Pertanian, 2014. Indonesia Negara Agraris. Diakses tanggal 7 April 2019.

Kotler, dan Keller, 2007, Manajemen Pemasaran, Jilid I, Edisi Kedua belas, Jakarta: PT. Indeks.

Kotler, P. 2012. Manajemen Pemasaran. Jakarta: Penerbit Erlangga. . 2012. Prinsip-Prinsip Pemasaran, Edisi 12 Jilid 1. Jakarta: Erlangga.

Laksana, 2010. Karakteristik Buah dan pohon pepaya, Agro Kates Mandiri.

Mubyarto, 1995. Pengantar Ekonomi Pertanian. Jakarta: LP3ES. 